\title{
Health Hazards of Solvents Exposure among Workers in Paint Industry
}

\author{
Aida Abd El Hamid Hassan, Safaa Abd El Moez Elnagar, Ihab Mohammadi El Tayeb, \\ Sara Abd El Halim Bolbol \\ Department of Community, Occupational and Environmental Medicine, Faculty of Medicine, Zagazig University, Zagazig, Egypt \\ Email: ihab_cphq@hotmail.com
}

Received September 10, 2013; revised October 10, 2013; accepted October 17, 2013

Copyright (C) 2013 Aida Abd El Hamid Hassan, et al. This is an open access article distributed under the Creative Commons Attribution License, which permits unrestricted use, distribution, and reproduction in any medium, provided the original work is properly cited.

\begin{abstract}
Background: Paints and coatings include paints, varnishes, lacquers, stains, printing inks and more. A wide variety of volatile solvents are used in paint and coating manufacturing including aliphatic and aromatic hydrocarbons, alcohols, ketones and consist of more than $30 \%$ of most of paints. At low or moderate concentrations, the organic solvents may cause transient symptoms such as euphoria, headache and dizziness. At high concentrations, anaesthesia and disturbances in respiration and circulation may occur and may lead to death. Long-term exposure may cause damage to the Central Nervous System (CNS), such as cognitive and emotional deficits. Methods: A cross sectional study was conducted among 92 male workers exposed to organic solvents on performing their job in Koratol Paint Factory in Alaama Village in Sharkia Governorate. Another group of $\mathbf{9 5}$ workers, not working with organic solvents were selected from the Faculty of Medicine in Zagazig University and considered as a control group. All participants in the study were subjected to a pre-designed questionnaire to collect information about personal, socio-demographic data, occupational history, use of personal protective equipments, frequently perceived health complaints which included irritation symptoms (skin, eye and nose) and Questions of the validated questionnaire for the neuropsychological symptoms (Q22). Results: The neuropsychological symptoms score (Q22) revealed that $63.04 \%$ of solvents exposed paint manufacturing workers had neuropsychological symptoms, compared to about only $\mathbf{2 . 1 \%}$ in control group and the difference was statistically significant. Regarding the relation between types of job done and results of neuropsychological symptoms score (Q22) there was increased risk for neuropsychological symptoms in production group than packing group $(\mathbf{O R}=13.94)$ and for the duration of work the risk increased in workers with duration over 15 years $(\mathbf{O R}=\mathbf{3 2 . 8 4})$. Logistic regression analysis showed that the most important predictors of neuropsychological symptoms were the type of job performed by the workers such as production or packing and their duration of work $\geq 15$ years. Conclusions: The paint industry workers were at increased risk of several irritant and neuropsychological symptoms which significantly related to exposure to paint and organic solvents.
\end{abstract}

Keywords: Paint Industry; Health Hazards; Zagazig; Egypt

\section{Introduction}

Paint products are widely used in industry to provide surface coating for protection against corrosion, for appearance as electrical insulation, for fire retardation and for other special purposes. Paints can be applied by a variety of processes including brush, roller, dip, flow, conventional air spray, airless spray, disk spraying and powder coating [1].

Organic solvents are widely used in industrial processes and in consumer products, commonly in the form of mixtures [2]. Commonly used solvents include iso- propanol, toluene, xylene, solvent mixtures such as white spirits and the chlorinated solvents, methylene chloride, trichloroethylene, and perchloroethylene. The largest end user is the coatings industry where solvents play an important role in the quality and durability of paints and varnishes [3].

In the processes involved in paint manufacture (such as mixing, milling, and shearing) workers are exposed to organic solvents that may cause a variety of symptoms, including transient symptoms of the central nervous system such as euphoria, headache, and dizziness at low or moderate concentrations and serious symptoms such as 
fainting and respiratory and circulatory failure at high concentrations. Some of these solvents such as benzene, toluene, and xylenes (BTXs) are known for suspected carcinogens and need effective control [4]. Long-term exposure may cause damage to the Central Nervous System (CNS), such as cognitive and emotional deficits. In particular, solvent related chronic encephalopathy (SRCE) has been described in several studies. Toxic effects of organic solvents were reported to harm liver, kidney and skin. Occupational exposure to mixtures of organic solvents has been evaluated in many activities, such as painting, paint spraying, floor-laying, shoe making, laundries, graffiti removers, etc. [5].

Organic solvents application grew to be wide and diverse in both developed and developing countries. The health effects of organic solvents have been known for more than a century. The introduction of chlorinated solvents in the 1920s led to reports of toxicity. Although solvents number in the thousands, only a few have been tested for neurotoxicity [6].

The advent of industry has increased the need for different solvents. While only a few organic solvents were used at the turn of the last century, their number has today increased to several hundreds. Although the primary concern about their usage used to be related to their causing fire and explosion, their toxicological properties have to be considered as well. The most important toxicological properties of organic solvents are their ability to evaporate and to dissolve fats. By dissolving fats, organic solvents can damage haematopoetic tissue, the reproductive system, the nervous system, skin and all parenchymatous organs rich in fats [7].

\section{Aim of the Work}

This work aimed to study the occupational health hazards due to solvents exposure among paint industry workers with the following objectives:

1) To study neuropsychological effects associated with solvents exposure among workers in the paint industry.

2) To identify occupational and personal risk factors that may be associated with these health problems.

\section{Subjects and Methods}

\subsection{Study Design and Setting}

A cross sectional study was carried out during the period from January to March 2008 at the Koratol Paint Factory in Alaama Village in Sharkia Governorate.

\subsection{Target Population}

The target population includes two groups of workers:

- Exposed group: It includes workers in Koratol Paint Factory exposed to organic solvents on performing their job, these solvents include mixture of aliphatic and aromatic solvents like: xylene, toluene, methyl isobutyl ketone (MIBK), methyl ethyl ketone (MEK), acetone, mineral spirits, thinners and others.

- Non-exposed group: It consists of workers not exposed to organic solvents at their current occupation nor even had a past history of exposure to solvents. They were taken from the Faculty of Medicine in $\mathrm{Za}$ gazig University.

\subsection{Sampling Technique}

The sample size was calculated through Epi-Info software version 6.1. Exposed group were 92 workers and they resembles the factory workers. Another group of 95 workers, not working with organic solvents were selected from the Faculty of Medicin in Zagazig University and considered as a control group and both groups were male workers. Both study and control group were comparable as regards age, residence, marital status and smoking habits.

\subsection{II-Data Collection (Methods)}

A pre-designed questionnaire was used to collect information from all participants about the following:

Part one: includes questions about Personal and sociodemographic.

Part two: includes questions about Occupational history, Presence of a side job or hobbies, and Use of personal protective equipments.

Part three: includes questions about any past or present medical problems, Symptoms of eye, nose, throat, and skin irritation, and Questions of the validated questionnaire for the neuropsychological symptoms (Q22) proposed by [8] Chen et al. (1999).

Questions 1 - 16 (Q1 - 16), summarized as psychological symptoms, were derived from the $\mathrm{Q}-16$ questionnaire used for screening in Nordic countries for the solvent syndrome (Axelson and Hogstedt, 1988), whereas questions 15 - 22 (Q15 - 22) may be summarized as neurological. Questions 15 and 16 are common to both.

\subsection{Ethical Considerations}

An informed consent was obtained from all participants of this study. The workers were told about the aim of the study, and they were informed that the data would be used for scientific purposes only. The workers were also given the right to refuse or participate in the study.

\subsection{Statistical Methods}

- The collected data were computerized and statistically analyzed using SPSS program (Statistical Package for Social Science) version 16.0. for the statistical calculations.

- Data coding was done, and neuropsychological scoring system was used to determine the workers who 
have these symptoms and who don't.

Qualitative data were represented as frequencies and percentages, Chi-square test was carried out for testing the association between the qualitative data whenever possible. The test results were considered significant when p-value $<\mathbf{0 . 0 5}$.

\section{Results}

Table 1 shows that the exposed and control group are comparable regarding socio demographic characteristics. The highest frequency was to the age group from 20 $<\mathbf{4 0}$ years being $\mathbf{7 0 . 7 \%}$ in exposed group and $\mathbf{6 5 . 3 \%}$ in control group. Most of the workers were rural residents and married, and only a small percentage of exposed and control group were illiterate $(\mathbf{4 . 3 \%}, \mathbf{7 . 4 \%})$ respectively.

Table 2 shows a higher frequency of psychological symptoms among paint manufacturing workers compared to control group. Having a headache at least once a week $\mathbf{8 0 . 4 \%}$ followed by being abnormally tired $\mathbf{7 6 . 0 8 \%}$ then feeling depressed without any particular reason $61.9 \%$ were the most frequent symptoms in exposed workers compared to controls and the difference were statistically significant.

Table 3 shows high statistically significant differences between exposed and control groups in having painful tingling in some parts of the body and for having problems with buttoning and unbuttoning. The two symptoms are considered as both neurological and psychological symptoms.

Table 1. Some socio demographic characteristics of solvents exposed workers and control group.

\begin{tabular}{|c|c|c|c|c|c|c|}
\hline \multirow{2}{*}{$\begin{array}{c}\text { Socio } \\
\text { demographic } \\
\text { characteristics }\end{array}$} & \multicolumn{2}{|c|}{$\begin{array}{c}\text { Exposed } \\
\text { group } N=92\end{array}$} & \multicolumn{2}{|c|}{$\begin{array}{c}\text { control group } \\
\quad \mathbf{N}=95\end{array}$} & \multirow{2}{*}{$\mathrm{X}^{2}$} & \multirow{2}{*}{$P$ value } \\
\hline & $\mathbf{N}$ & $\%$ & $\mathbf{N}$ & $\%$ & & \\
\hline \multicolumn{7}{|l|}{ Age } \\
\hline $20-<40$ & 65 & 70.7 & 62 & 65.3 & 0.62 & 0.43 \\
\hline $40-60$ & 27 & 29.3 & 33 & 34.7 & & NS \\
\hline \multicolumn{7}{|l|}{ Marital status } \\
\hline married & 85 & 92.4 & 90 & 94.7 & 0.43 & 0.51 \\
\hline not married & 7 & 7.6 & 5 & 5.3 & & NS \\
\hline \multicolumn{7}{|l|}{ Level of education } \\
\hline illiterate & 4 & 4.3 & 7 & 7.4 & $0.079^{*}$ & 0.78 \\
\hline read and write & 46 & 50.0 & 48 & 50.5 & $X^{2}$ for trend & NS \\
\hline school education & 42 & 45.7 & 40 & 42.1 & & \\
\hline \multicolumn{7}{|l|}{ Residence } \\
\hline Urban & 3 & 3.3 & 7 & 7.4 & Fisher exact & $\mathrm{t} \quad 0.33$ \\
\hline Rural & 89 & 96.7 & 88 & 92.6 & & NS \\
\hline
\end{tabular}

Table 4 shows that paint manufacturing workers are complaining from neurological symptoms more than their controls. Having difficulty in falling asleep 64.1\% followed by being unable to remember things although they are on the tip of their tongue $\mathbf{5 1 . 1 \%}$ then feeling weakness or unsteady in arms or legs $\mathbf{3 1 . 5 \%}$ are the most frequent symptoms. However none of exposed and control groups reported frequency of bumping into people or things when moving around.

Table 5 shows that about $\mathbf{6 3 . 0 4 \%}$ of solvents exposed workers had neuropsychological symptoms according to the results of the (Q22) by answering yes to 7 - 22 questions compared to about only (2.1\%) in control group and the difference was statistically significant.

Table 6 shows a significantly increased risk for neuropsychological symptoms in workers aged from 40 - 60 years compared to the workers of $\mathbf{2 0}-\mathbf{4 0}$ years $(\mathbf{O R}=$ 7.29), also the risk increased with decreased level of education being higher in illiterate and read and write workers than school education workers $(\mathrm{OR}=\mathbf{4 . 4 1}, \mathrm{OR}$ = 6.9). Regarding the duration of smoking and number of smoked cigarettes/day among smokers, the risk increased for duration of smoking more than 15 years $(\mathbf{O R}=$ 29.75) and for smoking 10 - 20 cigarettes/day $(\mathrm{OR}=$ 17.0).

Table 7 shows increased risk for neuropsychological symptoms in production group than packing group (OR $=$ 13.94). The risk also increased in workers with duration of work more than 15 years $(\mathrm{OR}=\mathbf{3 2 . 8 4})$, it shows that also the use of personal protective equipments doesn't decrease the risk for neuropsychological symptoms (OR = 1.35).

Table 8 shows that the most important predictors of neuropsychological symptoms were the type of job performed by the workers such as production or packing and the duration of work $\geq \mathbf{1 5}$ years.

\section{Discussion}

Early studies in Scandinavia suggested that long term, high level, solvent exposure might be associated with a syndrome of personality change, memory impairment, and neurological deficits variously termed chronic toxic encephalopathy (CTE), the psycho-organic syndrome or solvent neurotoxicity [3] The prevalence of individual psychological symptoms were found to be significantly higher among paint manufacturing workers for every question. These results are consistent with the previous studies conducted on spray painters exposed to a mixture of volatile organic solvents and noticed neurobehavioral changes in their neurobehavioral profile [9,10]. From these results, we can conclude that because there are more than nine million workers exposed to solvents in the workplace [11], this population is at risk for a high prevalence of psychiatric problems and the potential for 
Table 2. Psychological symptoms in solvents exposed workers and control group.

\begin{tabular}{|c|c|c|c|c|c|c|c|}
\hline \multirow{2}{*}{ Psychological symptoms } & \multicolumn{2}{|c|}{ Exposed group N = 92} & \multicolumn{2}{|c|}{ Control group N = 95} & \multirow{2}{*}{$\mathrm{X}^{2}$} & \multirow{2}{*}{$P$ value } & \multirow{2}{*}{ OR $(95 \% \mathrm{CI})$} \\
\hline & $\mathbf{N}$ & $\%$ & $\mathbf{N}$ & $\%$ & & & \\
\hline \multicolumn{8}{|l|}{ Short memory } \\
\hline Yes & 31 & 33.7 & 5 & 5.3 & 24.3 & 0.000 & 9.15 \\
\hline No & 61 & 66.3 & 90 & 94.7 & & HS & $(3.24-31.48)$ \\
\hline \multicolumn{8}{|l|}{ Relatives notice short memory } \\
\hline Yes & 12 & 13.04 & 2 & 2.1 & 8.1 & 0.000 & 6.97 \\
\hline No & 80 & 86.9 & 93 & 97.9 & & HS & $(1.47-65.44)$ \\
\hline \multicolumn{8}{|l|}{ Make notes } \\
\hline Yes & 12 & 13.04 & 3 & 3.15 & 6.2 & 0.000 & 4.60 \\
\hline No & 80 & 86.9 & 92 & 96.8 & & HS & $(1.18-26.10)$ \\
\hline \multicolumn{8}{|l|}{ Check things } \\
\hline Yes & 27 & 29.3 & 3 & 3.15 & 23.8 & 0.000 & 12.74 \\
\hline No & 65 & 70.7 & 92 & 96.8 & & HS & $(3.64-67.54)$ \\
\hline \multicolumn{8}{|l|}{ Hard to get meaning } \\
\hline Yes & 9 & 9.8 & 4 & 4.2 & 2.24 & 0.13 & 2.47 \\
\hline No & 83 & 90.2 & 91 & 95.8 & & S & $(0.66-11.33)$ \\
\hline \multicolumn{8}{|l|}{ Problem in concentrating } \\
\hline Yes & 30 & 32.6 & 2 & 2.1 & 30.7 & 0.000 & 22.50 \\
\hline No & 62 & 67.4 & 93 & 97.9 & & HS & $(5.31-198.42)$ \\
\hline \multicolumn{8}{|l|}{ Get irritated } \\
\hline Yes & 35 & 38.04 & 11 & 11.6 & 17.65 & 0.000 & 4.69 \\
\hline No & 57 & 61.9 & 84 & 88.4 & & HS & $(2.10-11.03)$ \\
\hline \multicolumn{8}{|l|}{ Feel depressed } \\
\hline Yes & 57 & 61.9 & 7 & 7.4 & 61.7 & 0.000 & 20.47 \\
\hline No & 35 & 38.04 & 88 & 92.6 & & HS & $(8.13-57.37)$ \\
\hline \multicolumn{8}{|l|}{ Abnormally tired } \\
\hline Yes & 70 & 76.08 & 8 & 8.4 & 88.01 & 0.000 & 34.60 \\
\hline No & 22 & 23.9 & 87 & 91.6 & & HS & $(13.69-93.44)$ \\
\hline \multicolumn{8}{|l|}{ Have palpitation } \\
\hline Yes & 48 & 52.2 & 2 & 2.1 & 59.8 & 0.000 & 50.73 \\
\hline No & 44 & 47.8 & 93 & 97.9 & & HS & $(12.10-441.14)$ \\
\hline \multicolumn{8}{|l|}{ Pressure in chest } \\
\hline Yes & 55 & 59.8 & 3 & 3.1 & 70.04 & 0.000 & 45.59 \\
\hline No & 37 & 40.2 & 92 & 96.8 & & HS & $(13.21-236.50)$ \\
\hline \multicolumn{8}{|l|}{ Headache } \\
\hline Yes & 74 & 80.4 & 6 & 6.3 & 104.9 & 0.000 & 60.98 \\
\hline No & 18 & 19.6 & 89 & 93.7 & & HS & $(21.58-191.35)$ \\
\hline
\end{tabular}


Table 3. Neuropsychological symptoms in solvents exposed workers and control group.

\begin{tabular}{|c|c|c|c|c|c|c|c|}
\hline \multirow{2}{*}{ Neuropsychological symptoms } & \multicolumn{2}{|c|}{ Exposed group $\mathbf{N}=92$} & \multicolumn{2}{|c|}{ Control group $\mathrm{N}=95$} & \multirow{2}{*}{$X^{2}$} & \multirow{2}{*}{ P value } & \multirow{2}{*}{ OR $(95 \% \mathrm{CI})$} \\
\hline & $\mathbf{N}$ & $\%$ & $\mathbf{N}$ & $\%$ & & & \\
\hline Yes & 58 & 63.04 & 10 & 10.5 & 55.7 & 0.000 & 14.50 \\
\hline No & 34 & 36.9 & 85 & 89.5 & & HS & $(6.33-35.06)$ \\
\hline \multicolumn{8}{|l|}{ Buttoning \& unbuttoning } \\
\hline Yes & 8 & 8.4 & 1 & 1.05 & 5.9 & 0.02 & 8.95 \\
\hline No & 84 & 88.4 & 94 & 98.9 & & $\mathrm{~S}$ & $(1.15-401.37)$ \\
\hline
\end{tabular}

Table 4. Neurological symptoms in solvents exposed workers and control group.

\begin{tabular}{|c|c|c|c|c|c|c|c|}
\hline \multirow{2}{*}{ Neurological symptoms } & \multicolumn{2}{|c|}{ Exposed group $\mathrm{N}=92$} & \multicolumn{2}{|c|}{ Control group N = 95} & \multirow{2}{*}{$\mathrm{X}^{2}$} & \multirow{2}{*}{$P$ value } & \multirow{2}{*}{ OR $(95 \%$ CI $)$} \\
\hline & $\mathbf{N}$ & $\%$ & $\mathbf{N}$ & $\%$ & & & \\
\hline \multicolumn{8}{|l|}{ Dizziness } \\
\hline Yes & 11 & 11.9 & 2 & 2.1 & 7.01 & 0.008 & 6.31 \\
\hline No & 81 & 88.04 & 93 & 97.9 & & HS & $(1.31-59.79)$ \\
\hline Hands tremble & & & & & & 0.000 & \\
\hline Yes & 20 & 21.7 & 3 & 3.16 & 14.9 & & 8.52 \\
\hline No & 72 & 78.3 & 92 & 96.8 & & HS & $(2.37-46.04)$ \\
\hline \multicolumn{8}{|l|}{ Weakness arms or legs } \\
\hline Yes & 29 & 31.5 & 6 & 6.3 & 19.5 & 0.000 & 6.83 \\
\hline No & 63 & 68.5 & 89 & 89.5 & & HS & $(2.56-21.12)$ \\
\hline \multicolumn{8}{|c|}{ Remember things on tip of tongue } \\
\hline Yes & 47 & 51.1 & 3 & 3.2 & 54.8 & 0.000 & 32.03 \\
\hline No & 45 & 48.9 & 92 & 96.8 & & HS & $(9.34-166.43)$ \\
\hline \multicolumn{8}{|l|}{ Difficulty falling asleep } \\
\hline Yes & 59 & 64.1 & 7 & 7.4 & 65.9 & 0.000 & 22.48 \\
\hline No & 33 & 35.9 & 88 & 92.6 & & HS & $(8.89-63.08)$ \\
\hline
\end{tabular}

Table 5. Results of (Q22) neuropsychological symptoms score among solvents exposed workers and control group.

\begin{tabular}{|c|c|c|c|c|c|c|c|}
\hline \multirow{2}{*}{ Neuropsychological symptoms } & \multicolumn{2}{|c|}{ Exposed group $\mathrm{N}=92$} & \multicolumn{2}{|c|}{ Control group $\mathrm{N}=95$} & \multirow{2}{*}{$\mathrm{X}^{2}$} & \multirow{2}{*}{$P$ value } & \multirow{2}{*}{ OR $(95 \% \mathrm{CI})$} \\
\hline & $\mathrm{N}$ & $\%$ & $\mathrm{~N}$ & $\%$ & & & \\
\hline No symptoms (<7Q) & 34 & 36.9 & 93 & 97.9 & \multirow{2}{*}{79.6} & \multirow{2}{*}{$\begin{array}{l}0.000 \\
\text { HS }\end{array}$} & \multirow{2}{*}{$\begin{array}{c}79.32 \\
(18.73-688.32)\end{array}$} \\
\hline $7-22 Q$ & 58 & 63.04 & 2 & 2.1 & & & \\
\hline
\end{tabular}

the development of substantial psychiatric disorders secondary to such exposure is great It was noticed from the results of this study that neurological symptoms are prevalent among workers exposed to organic solvents over non exposed. In this study, the most frequent symptoms that appear in the workers exposed to organic sol- vents include difficulty in falling asleep painful tingling in some parts of the body, can't remember things although they are on the tip of their tongue and weakness in the arms or legs. it was found to be in agreement with Several epidemiological studies which suggested that, exposure to mixture of organic solvents may contribute 
Table 6. Relation between some socio-demographic characteristics and Smoking habits of solvents exposed workers and results of Q22 score.

\begin{tabular}{|c|c|c|c|c|c|c|c|}
\hline \multirow{3}{*}{ Variables } & \multicolumn{4}{|c|}{ Neuropsychological symptoms score } & \multirow{3}{*}{$\mathrm{X}^{2}$} & \multirow{3}{*}{$P$ value } & \multirow{3}{*}{ OR $(95 \% \mathrm{CI})$} \\
\hline & \multicolumn{2}{|c|}{ Present (7 - 22Q) } & \multicolumn{2}{|c|}{ Absent $(<7 Q)$} & & & \\
\hline & $\mathbf{N}$ & $\%$ & $\mathbf{N}$ & $\%$ & & & \\
\hline \multicolumn{8}{|c|}{ Socio demographic characteristics } \\
\hline \multicolumn{8}{|l|}{ Age: } \\
\hline 20 - 40 years & 34 & 52.3 & 31 & 47.7 & 10.9 & 0.001 & 7.29 \\
\hline $40-60$ years & 24 & 88.9 & 3 & 11.1 & & & $(1.89-40.74)$ \\
\hline \multicolumn{8}{|l|}{ Residence: } \\
\hline Urban & 1 & 33.3 & 2 & 66.7 & 1.28 & 0.26 & 3.56 \\
\hline Rural & 57 & 64.0 & 32 & 36.0 & & & $(0.18-213.78)$ \\
\hline \multicolumn{8}{|l|}{ Level of education: } \\
\hline Illiterate & 3 & 75.0 & 1 & 25.0 & $16.5^{*}$ & 0.000 & $4.41(0.31-240.6)$ \\
\hline Read and write & 38 & 82.6 & 8 & 17.4 & $\mathrm{X}^{2}$ for trend. & & $6.9(2.38-21.15)$ \\
\hline School education & 17 & 40.5 & 25 & 59.5 & & & 1.00 \\
\hline \multicolumn{8}{|c|}{ Smoking habits } \\
\hline \multicolumn{8}{|l|}{ Smoking status: } \\
\hline Current smoker & 19 & 67.9 & 9 & 32.1 & 0.4 & 0.53 & 1.35 \\
\hline Non-smoker ${ }^{*}$ & 39 & 60.9 & 25 & 39.1 & & & $(0.48-3.85)$ \\
\hline \multicolumn{8}{|l|}{ Smoking Duration ${ }^{* *}$} \\
\hline$<15$ years & 2 & 22.2 & 7 & 77.8 & 12.7 & 0.000 & 29.75 \\
\hline$\geq 15$ years & 17 & 89.5 & 2 & 10.5 & & & $(2.56-419.54)$ \\
\hline \multicolumn{8}{|c|}{ Number of ciga rettes/day ${ }^{* *}$} \\
\hline 1 - 10 cigarettes & 2 & 25.0 & 6 & 7.5 & 9.4 & 0.002 & 17.0 \\
\hline 10 - 20 cigarettes & 17 & 85.0 & 3 & 15.0 & & & $(1.69-219.19)$ \\
\hline
\end{tabular}

${ }^{*}$ Non-smoker $=$ never smoked + ex-smoker; ${ }^{* *}$ For smokers only.

to an increased risk of neuropsychological disorders [12].

However, by contrast with this some studies have not shown a relation between exposure to solvents and evidence of neuropsychological disease [13]. It is to be expected that there would be conflicting published results, as adverse effects of solvents are likely to be dose dependent, and many groups of workers are no longer exposed to high concentrations.

A total score of all symptoms, summarized from Q1 22, showed that paint manufacturing workers had high scores, compared with controls, for both psychological and neurological symptoms. Regarding the level of education, the odds ratio (OR) showed increased risk with decrease level of education being higher in illiterate and read and write workers than school education workers. It has been suggested that low intellectual capacity may predispose to the development of neurotoxic effects of organic solvents and the duration of education is known to affect neurobehavioral performance, this was consistent with previous studies $[9,14]$.

Results of this study showed increased risk for neuropsychological symptoms with increased age being higher for age 40 - 60 years $(\mathbf{O R}=\mathbf{7 . 2 9})$. This was consistent with several studies which showed that the neurobehavioral performance decreased with age $[8,9,15]$.

This study also showed increased risk for neuropsychological symptoms with tobacco smoking $(\mathbf{O R}=\mathbf{1 . 3 5})$ and this risk increased with increase the amount of smoking being higher with smoking 10 - 20 cigarettes $(\mathbf{O R}=\mathbf{1 7 . 0})$. These results are found to be in agreement with some studies which showed relation between smoking and headache which was related to daily smoking 
Table 7. Relation between type of job done by the paint manufacturing workers, duration of occupation, use of personal protective equipments (PPE) and results of Q22 score.

\begin{tabular}{|c|c|c|c|c|c|c|c|}
\hline \multirow{3}{*}{ Variables } & \multicolumn{4}{|c|}{ Neuropsychological symptoms score } & \multirow{3}{*}{$X^{2}$} & \multirow{3}{*}{$P$ value } & \multirow{3}{*}{ OR $(95 \% \mathrm{CI})$} \\
\hline & \multicolumn{2}{|c|}{ Present (7 - 22Q) } & \multicolumn{2}{|c|}{ Absent $(<7 Q)$} & & & \\
\hline & $\mathbf{N}$ & $\%$ & $\mathbf{N}$ & $\%$ & & & \\
\hline \multicolumn{8}{|c|}{ Type of job and duration of work } \\
\hline \multicolumn{8}{|l|}{ Type of job: } \\
\hline Production & 27 & 93.1 & 2 & 6.9 & 16.4 & 0.000 & 13.94 \\
\hline Packing & 31 & 49.2 & 32 & 50.8 & & & $(2.99-127.74)$ \\
\hline \multicolumn{8}{|c|}{ Duration of work: } \\
\hline$<15$ years & 19 & 37.3 & 32 & 62.7 & 32.6 & 0.000 & 32.84 \\
\hline$\geq 15$ years & 49 & 95.1 & 2 & 4.9 & & & $(6.87-299.02)$ \\
\hline \multicolumn{8}{|c|}{ Use of PPE } \\
\hline Yes & 19 & 67.9 & 9 & 32.1 & 0.4 & 0.53 & 1.35 \\
\hline No & 39 & 60.9 & 25 & 39.1 & & & $(0.48-3.85)$ \\
\hline
\end{tabular}

Table 8. Logistic regression analysis for significant predictors of neuropsychological symptoms among solvents exposed paint manufacturing workers.

\begin{tabular}{cccccc}
\hline Independent factors & B & S.E & Wald & P value & O.R (95\% CI ) \\
\hline Control workers & & & 35.8 & 0.000 & $192.9(26.8-1386.8)$ \\
production workers & 5.2 & 1.00 & 27.3 & 0.000 & $1083.1(100.7-11648.3)$ \\
$\quad$ packing workers & 6.9 & 1.2 & 33.2 & 0.000 & $23.4(4.9-109.6)$ \\
Duration of work $\geq 15$ years & 3.1 & 0.8 & 16.0 & 0.000 & \\
\hline
\end{tabular}

rate and pack-year history [16,17], also relation between smoking and sleep disturbance $[18,19]$ and these symptoms were attributed to nicotine exposure.

Nicotine has vascular activities that increase the risk of tension and cluster headaches, also smoking can cause restlessness and smokers usually sleep very lightly at night and will wake up at the slightest noise, [20] in an epidemiological study, reported that active smoking was associated with difficulty initiating sleep (DIS), excessive daytime sleepiness (EDS), and difficulty waking up.

In contrast with these results, previous studies showed that the ORs for smoking and amount of tobacco smoking in relation to neuropsychological symptoms were not significant $[8,15,21]$.

Regarding the duration of work the odds ratio (OR) showed increased risk with increase years of exposure to paints more than 15 years $(\mathrm{OR}=\mathbf{3 2 . 8 4})$. The possibility that the neuropsychological symptoms were caused by exposure to substances at work is suggested by the exposure response relation, relying on years worked in the paint manufacturing industry.

These results were in agreement with several studies that reported significant associations between duration of exposure to aliphatic and aromatic hydrocarbons and neuropsychological symptoms $[8,15,22]$.

This study showed also association between neuropsychological symptoms and the type of job performed by the workers being higher in production group than packing group $(\mathbf{O R}=\mathbf{1 3 . 9 4})$. This may be explained by the higher exposure in production group as they work in assembling of raw material, mixing, dispersing, thinning and adjusting sectors so they are more exposed to hazardous materials like pigments, dyes, additives and different types of solvents (e.g; xylene, toluene, methyl isobutyl ketone (MIBK), methyl ethyl ketone (MEK), acetone, mineral spirits, thinners and others). These results were found to be consistent with a previous study that showed that production group had higher rate of exposure than packing group [23].

Regarding the use of personal protective equipments (PPE) in the form of gloves, the odds ratio (OR) showed that the use of PPE doesn't decrease the risk for neuropsychological symptoms $(\mathbf{O R}=\mathbf{1 . 3 5})$. This is mainly due to increased dermal exposure as the use of these PPE was 
interrupted and thus cause increased neuropsychological symptoms.

On logistic regression analysis, it was found that the most important predictors of neuropsychological symptoms among solvents exposed workers were the type of job performed whether production or packing $(\mathbf{O R}=$ 192.9 for production group, $\mathrm{OR}=\mathbf{1 0 8 3 . 1}$ for packing group) and duration of work $\geq \mathbf{1 5}$ years $(\mathrm{OR}=\mathbf{2 3 . 4}$ ). These results were supported by previous studies which concluded that neuropsychological symptoms were related to exposure to organic solvents and significantly associated with type of work performed and duration of exposure $[9,21,22]$.

\section{Constrains of the Study}

- Some workers refused to cooperate despite sufficient explanations.

- There was some hesitation of the factory workers to admit having symptoms for fear of being fired from their current job.

\section{Recommendations}

1) Stress the importance of efficient and regular replacement and periodic medical examination especially to production workers.

2) Train employees in solvent safety.

3) All workers should be trained on the first-aid measures for any chemical they are using.

4) Emergency eyewash stations and whole body showers should be installed in workplaces where solvents are used.

5) Maintain good hygiene practices.

6) Consideration should be given to the use of waterbased paint instead of solvents based paint.

7) Call to launch a syndicate for paint workers to collect statistical data about workers aiming for protection of their health.

\section{Conclusion}

The study has shown that the frequency of the irritant symptoms (eye, nose and skin irritation) was significantly related to exposure to paint and organic solvents. Also, paint industry workers were at increased risk of several neuropsychological symptoms. These are often minor and therefore easily dismissed as unimportant or accepted as "part of the job". Also, the knowledge about the safety measures of commonly used solvents is not understood and the need of pre-employment training is recommended on ongoing basis.

\section{REFERENCES}

[1] N. M. El Mahdy and N. M. Radwan, “Assessment of
Different Health Hazards in Painting Industry," The Egyptian Journal of Occupational Medicine, Vol. 33, No. 2, 2009, pp. 211-232.

[2] Y. Gong, R. Kishi and S. Kasai, "Visual Dysfunction in Workers Exposed to a Mixture of Organic Solvents," NeuroToxicology, Vol. 24, No. 4-5, 2003, pp. 703-710. http://dx.doi.org/10.1016/S0161-813X(03)00034-2

[3] F. Dick, "Solvent Neurotoxicity," Occupational and Environmental Medicine, Vol. 63, No. 3, 2006, pp. 221-226. http://dx.doi.org/10.1136/oem.2005.022400

[4] A. Karimi, M. Jahangiri, F. Zare and M. Amin, "Respirator Cartridge Change Scheduling in a Paint Plant in Iran," Archives of industrial hygiene and toxicology, Vol. 64, No. 1, 2013, pp. 133-138.

http://dx.doi.org/10.2478/10004-1254-64-2013-2256

[5] M. Vitali, F. Ensabella, D. Stella and M. Guidotti, "Eposure to Organic Solvents among Handicraft Car Painters: A Pilot Study in Italy," Industrial Health, Vol. 44, No. 2, 2006, pp. 310-317.

http://dx.doi.org/10.2486/indhealth.44.310

[6] "Rutchiks: Organic Solvents," 2006.

http://emedicine.medscape.com/article/1174981-overview

[7] J. Hoek, M. Verberk, G. Laan, G. Hageman and T. Ned, "Solvent Induced Chronic Encephalophathy; The Solvent Team Project," Nederlands Tijdschrift voor Geneeskunde, Vol. 145, No. 6, 2001, pp. 256-260.

[8] R. Chen, F. Dick and A. Seaton, "Health Effects of Solvent Exposure among Dockyard Painters: Mortality and Neuropsychological Symptoms," Occupational and Environmental Medicine, Vol. 56, No. 6, 1999, pp. 383-387.

[9] C. Lee, K. Jeong, Y. Kim, C. Yoo, J. Lee and Y. Choi, "Neurobehavioral changes of Shipyard Painters exposed to mixed organic solvents," Industrial Health, Vol. 43, No. 2, 2005, pp. 320-326.

[10] S. Zaidi, R. Tiwari, S. Gandhi, K. Patel, S. Kumar and H. Saiyed, "Neurobehavioral Effects and Hormones Profile among Spray Painter," Industrial Health, Vol. 44, No. 1, 2006, pp. 93-97.

[11] NIOSH, "Current Intelligence Bulletin 48. Organic Solvent Neurotoxicity," US Department of Health and Human Services, Ohio, 1987.

[12] M. Yücel, M. Takagi, M. Walterfang and D. Lubman, "Toluene Misuse and Long-Term Harms: A Systematic Review of the Neuropsychological and Neuroimaging Literature," Neuroscience \& Biobehavioral Reviews, Vol. 32, No. 5, 2008, pp. 910-936.

[13] J. Hooisma, H. Hanninen and H. Emmen, "Behavioral Effects of Exposure to Organic Solvents in Dutch Painters," Neurotoxicology and Teratology, Vol. 15, No. 6, 1993, pp. 397-406.

[14] M. Viaene, W. Pauwels, H. Veulemans, H. Roels and R. Masschelein, "Neurobehavioural Changes and Persistence of Complaints in Workers Exposed to Styrene in a Polyester Boat Building Plant: Influence of Exposure Characteristics and Microsomal Epoxide Hydrolase Phenotype," Occupational and Environmental Medicine, Vol. 58, No. 2, 2001, pp. 103-115.

[15] S. Kang, "The Applicability of WHO-NCTB in Korea," 
Neurotoxicology, Vol. 21, No. 5, 2000, pp. 697-702.

[16] J. Payne, B. Stetson, M. Stevens, C. Johnson, D. Penzien and B. Dorsten, "The Impact of Cigarette Smoking on Headache Activity in Headache Patients," Headache: The Journal of Head and Face Pain, Vol. 31, No. 5, 1991, pp. 329-332.

[17] A. Aamodt, L. Stovner, K. Hagen, G. Brathen and J. Zwart, "Headache Prevalence Related to Smoking and Alcohol Use. The Head-HUNT Study," European Journal of Neurology, Vol. 13, No. 11, 2006, pp. 1233-1238.

[18] B. Phillips and F. Danner, "Cigarette Smoking and Sleep Disturbance," Archives of Internal Medicine, Vol. 155, No. 7, 1995, pp. 734-737. http://dx.doi.org/10.1001/archinte.1995.00430070088011

[19] A. Zailinawati, K. Ariff, M. Nurjahan and C. Teng, "Epidemiology of Insomnia in Malaysian Adults: A Community-Based Survey in 4 Urban Areas," Asia-Pacific Journal of Public Health, Vol. 20, No. 3, 2008, pp. 224-233.
[20] D. Wetter and T. Young, "The Relation between Cigarette Smoking and Sleep Disturbance," Preventive Medicine, Vol. 23, No. 3, 1994, pp. 328-362.

[21] P. Nassiri and F. Golbabai, "Assessment of Hydrocarbons in Workers' Exposure a Paint Industry," Industrial Health, Vol. 37, No. 4, 1999, pp. 469-473.

http://dx.doi.org/10.2486/indhealth.37.469

[22] K. Andersson and R. Hockey, "Effect of Cigarette Smoking on Incidental Memory," Psychopharmacologia, Vol. 52, No. 3, 1977, pp. 223-229.

[23] L. Nilson, G. Sallsten and S. Hagberg, "Influence of Solvent Exposure and Aging on Cognitive Functioning: An 18 Year Follow Up of Formerly Exposed Floor Layers and Their Controls," Occupational and Environmental Medicine, Vol. 59, No. 1, 2002, pp. 49-57. 